\title{
Effect of Neonatal Care Education Adopted from Intended Midwifery Textbooks on Knowledge, Attitude and Performance of Midwifery Teachers
}

\author{
Seyyedeh Fatemeh Vasegh Rahimparvar1, Khadijeh Kharaghani², Maryam Modarres³, Mitra Zolfaghari", \\ Anoushirvan Kazemnejad ${ }^{5}$
}

1Department of Midwifery, Tehran University of Medical Sciences, Tehran, Iran. ${ }^{2}$ Department of Midwifery, Tehran

University of Medical Sciences, Tehran, Iran. ${ }^{3}$ Department of Midwifery, Tehran University of Medical Sciences,

Tehran, Iran. ${ }^{4}$ Department of Telecommunication Planning, Tehran's Virtual University of Medical Sciences, Tehran, Iran. ${ }^{5}$ Department of Biostatistics, Tarbiat Modares University, Tehran, Iran.

\section{ABSTRACT}

\section{BACKGROUND}

Students' educational resources play an important role in the formation of their professional identities and their learning. It is necessary to investigate the knowledge and attitudes of the individuals associated with a profession in order to make changes and optimize the education, as well as improving the performance of the individuals who serve it. The purpose of this study was to determine the effects of neonatal care education on knowledge, attitude and performance of midwifery teachers according to intended midwifery textbooks.

\section{METHODS}

This is a single-group intervention study with pre- and post-test design. The research population included all midwifery teachers of Iranian public and private universities that were selected in an available manner. At first, 250 midwifery teachers were invited for the study. 67 of them filled in the pre-test questionnaire and participated in a virtual training program developed by researchers in Navid educational system of the school of virtual medicine of Tehran University of Medical Sciences. Teachers were provided with the educational contents adapted from intended midwifery textbooks within a span of 8 weeks. The teachers completed the post-test questionnaire one week after the end of the education. Data was analysed using SPSS software, descriptive statistics, paired T-test and Wilcoxon test.

\section{RESULTS}

According to the results, the mean scores of the teachers' knowledge before and after education were $8.19 \pm 2.41$ and $11.43 \pm 2.54$ respectively (out of a total score of 15 ). The mean score of the teachers' attitude before and after education was $45.97 \pm 9.04$ and $49.37 \pm 7.37$ respectively (out of a total score of 70 ) and eventually the mean score of the teachers' performance before and after education was $109.82 \pm 10.23$ and $113.46 \pm 9.46$ respectively (out of a total score of 125 ). The results revealed that education based on intended midwifery textbooks significantly increase the knowledge $(\mathrm{p}<0.001)$, attitude $(\mathrm{p}=0.004)$ and performance $(\mathrm{p}=0.001)$ score.

\section{CONCLUSIONS}

Virtual education based on intended midwifery textbooks had a positive impact on the knowledge, attitude and performance of midwifery teachers. It is recommended that virtual neonatal care education adapted from intended midwifery textbooks be used for education of midwifery teachers.

\section{KEY WORDS}

Knowledge, Attitude, Performance, Textbooks, Midwifery Teachers
Corresponding Author: Khadijeh Kharaghani, Master in Midwifery, Tehran University of Medical Sciences, Tehran, Iran.

E-mail: kharaghanimw@gmail.com

DOI: $10.14260 / \mathrm{jemds} / 2019 / 764$

Financial or Other Competing Interests: None.

How to Cite This Article:

Rahimparvar SFV, Kharaghani K, Modarres $M$, et al. Effect of neonatal care education adopted from intended midwifery textbooks on knowledge, attitude and performance of midwifery teachers. J. Evolution Med. Dent. Sci. 2019;8(47):3535-3539, DOI: 10.14260/jemds/2019/764

Submission 29-09-2019,

Peer Review 07-11-2019,

Acceptance 13-11-2019,

Published 25-11-2019. 


\section{BACKGROUND}

Midwifery is an international profession.(1) In the international definition of midwife suggested by the International Confederation of Midwives (ICM), the midwife can take responsibility for childbirth and have the ability to take care of the newborn, including prophylactic measures, promotion of normal vaginal delivery, and the diagnosis of abnormal conditions of the mother and her baby.(2),(3) Taking care of newborns entail evaluation of their condition, adaptation to life out of the womb, their primary needs, the benefits of different methods of warming up, methods and tools for measuring gestational age, characteristics of the underweights and their specific needs, characteristics of a healthy one, normal growth patterns of the premature, healthy neonate growth patterns, different specific findings in the healthy newborn, elements and components of health promotion and prevention of illness in newborns comprising essential daily care, immunization needs, dangers and benefits from the beginning of childhood to the end of it, traditional or cultural methods related to baby care, feeding principles and options, and special signs and symptoms.(4) The teaching of the above items as professional attributes to midwifery students is one of the most important duties of the authorities responsible for developing midwifery curriculum as regards neonatal care in each country.(2)

It plays an important role in learning professional duties to educate students. Nelson's essential pediatrics textbook has been suggested not only as a main reference in undergraduate midwifery curriculum, (5) but also as a main reference for the postgraduate entrance exam by the Ministry of Health.(6) The textbook is particularly intended for pediatricians, and one of their references. The study of pediatric textbooks seems to be beneficial for midwifery students but cannot replace midwifery ones. The lack of clarified job descriptions and inconsistencies between theoretical and practical learning is among important educational problems of midwifery student.(7) In intended midwifery textbooks, there are topics that little are they paid regard in pediatric textbooks. Furthermore, it is not necessary for midwifery students and midwives to know all the topics of the pediatric textbooks. One of the major advantages of intended midwifery textbooks over the pediatric is that it clearly tells the midwife what are her duties and professional limitations, as well as helping them not to be confused.(8) In fact, the study of intended midwifery textbooks not only provides them with all the information that a midwife must know, but familiarizes them with professional duties. In the midwifery textbooks, for example, it is clearly distinguished between the responsibilities of the midwife and physician how to carry out a physical examination of the neonate.(4)

Midwives are members of the medical community whose aim is to promote the health of the mother and baby, (9) so midwives-educating program is of paramount importance.(10) Nowadays, modern educational methods have been taken into consideration in teaching teachers and students. It is one of them to employ E-learning method. The evolution of these methods is in a direction that each person can learn at any time and place with his or her own facilities and within the timeframe he/she sets aside for.(11) Over a span of teaching, researchers have found many problems as regards this course of study, i.e. pediatrics class. For instance, this course is presented by pediatricians based on Nelson's essential pediatrics textbook, primarily intended for pediatricians. It is hereby obvious that graduate midwifery students will not be able to play their own role as a midwife towards neonates. Researchers who conducted in-depth study both on intended midwifery textbooks in developed countries and on ICM recommendations as well as existing related studies found that it is necessary to make changes in terms of the textbook and teacher. Therefore, it is recommended that contents of the midwifery textbook be provided by midwifery instructors based on midwifery curriculum, and hence midwifery students are able to effectively play their own role as a midwife, as well as the extent of their professional duties are distinguished from pediatricians. In this regard, the knowledge of midwifery teachers about intended midwifery textbooks, besides their attitude and practical manner towards this educational content is all-important. In this study, E-learning method has been applied.

\section{METHODS}

This quasi-experimental study is a pre- and post-design single-group interventional study. The research population included 250 midwifery teachers from the public and private universities countrywide that were selected in an available manner. Study-entering criteria entailed: Membership in the midwifery communication, having master or $\mathrm{PhD}$ degrees in midwifery, being permanent staff/ fixed term employee/ contract one or apprentice, having theoretical or clinical track record in teaching or willing to teach this course of study and at least having 6 months of working under her belt, as well as access to the Internet. Study-withdrawing criteria comprised: absence from participating in more than three virtual education courses of the designed study and also reluctance to continue.

The data-collecting means was a researcher-made questionnaire. It needs to be mentioned that in order to investigate the goals of this research, the researchers were required to prepare a questionnaire. The researcher-made questionnaire was comprised of four sections including demographic characteristics (14 items): name of the university, academic degree, university name at the last level, age, educational experience, clinical work experience, employment status, faculty status, academic rank, marital status, track record in theoretically teaching the pediatrics class at midwifery undergraduate level, track record in clinically teaching the pediatrics class at midwifery undergraduate level, the track record in taking part in physiological delivery, newborn-resuscitating, and breast feeding workshops (held by the Ministry of Health). Questions comprised: Knowledge Questions (15 four-choice questions about neonatal care based on intended midwifery textbooks Myles and Warny), attitude questions (14 questions about the attitude of midwifery teachers towards neonatal care according to intended midwifery textbooks) and performance questions (5 questions about the performance of midwifery teachers concerning neonatal care based on the content of the intended Midwifery textbooks Myles and Warny in the form of a scenario). Questions related to knowledge consisted of 4 choices that scored 1 for the correct answer and zero score for the wrong answer was considered. For the attitude questions, 
the Likert scale (Grade 1 to 5 ) was employed: I am totally in agreement (Score 5), I agree (Grade 4), I have no idea (score 3), I disagree (Score 2), totally opposite (Score 1), and also for performance questions: always I do (Score 5), sometimes I do (Grade 4), I'm not sure that I do (Score 3), I rarely do (Score 2) and I never do it (Score 1). Academic credentials (Apparent and content) of the instrument were confirmed during the two sessions of the panel consisting of 12 midwifery professors that had more than 10 years' working under their belt in Tehran Nursing and Midwifery school (mean CVR and CVI questionnaire were 89.8 and 0.86 respectively).

In order to determine the reliability of the questionnaire, it was emailed to 75 midwifery faculty members of the universities. 30 faculty members, eventually, completed the questionnaire. Both Cronbach's alpha coefficient and internal consistency was applied to determine the reliability of the questionnaire. The measures yield 0.89 , so the reliability of the questionnaire was confirmed (more than 0.7 acceptable).

The email of midwifery teachers is available on college websites. After empowered by the Ethics Committee (approval number: IR.TUMS.FNM.REC1397.054) in Tehran University of Medical Sciences and obtaining the necessary permissions from the relevant authorities, the survey was conducted using the virtual education system of Tehran University of Medical Sciences (Navid system: http://navid.tums.ac.ir). Emails of the eligible participants were countrywide collected using the website of Nursing-Midwifery Schools. Then, a questionnaire, invitation and authorization of the Ethics Committee of Tehran University of Medical Sciences, along with an explication of how to connect Navid's E-learning system, how to receive educational content, and how to evaluate members in a group way or, if necessary, individually were emailed to them. After participants were assured of confidentiality of information, they were asked to submit phone number and national identification code if wishing to take part in. The reminders were also emailed weekly for 1 month in order to remind them to participate.

After 5 weeks, 74 of the participants filled in the pre-test questionnaire and along with both their national ID code and phone number emailed to researchers. The method of participation in the training course was step by step designed and explained. Then, each of the research units was not only assigned a username and password to access the training program, but also emailed to them. The research units were allowed to enter the educational system 24 hours a day using their own username and password, so they could access the content of the developed education.

Because of being fully occupied with work, seven participants were excluded from the study. Sixty-seven participants entered the virtual education system, and weekly they received a part of the content of the neonatal care based on intended midwifery textbooks (including text, photos, and videos). Educational content during the first week to eighth comprised of: identifying a healthy baby at birth, babies with low birth weight, congenital anomalies, injuries such as bleeding, significant problems with newborns, infant feeding, seizure and also cardiopulmonary resuscitation. The subjects were provided with all of the educational content within a span of 8 weeks. The topic of identifying a healthy baby at birth was held as a rehearsal content in the continuing education system and 3.5 rehearsal score were awarded to the training participants who received the passing grade. Throughout the study, participants were followed up via e-mail, texting, and phone calls, besides trouble shooting any probable problems such as system-entering errors. In order to answer participants' question and keep them better informed, a chatting group was created on Telegram messenger in the name of midwifery teachers, and the subjects joined it.

Two weeks after completing the training course, the research units completed the post-test questionnaire and emailed them to the researchers. Eventually, the collected data were analyzed by both SPSS software and descriptive statistics for preparing tables and calculating mean and standard deviation, as well as inferential statistics using paired t-test, Wilcoxon.

\section{RESULTS}

Gathered information (Table 1) showed that most of the participants were working in public universities $(67.2 \%)$ and have the master's degree in midwifery (62.7\%). $13.4 \%$ of the subjects had theoretically taught this course of study at undergraduate level, with a maximum teaching span of 4 courses and also $34.3 \%$ of them had clinically teaching experience under their belt with a maximum span of 6 courses. The knowledge-assessing findings (Table 2) showed an increase in the mean score of the subjects' knowledge after training, from $8.19 \pm 2.41$ to $11.43 \pm 2$. $54(\mathrm{p}<0.001)$. The findings of the attitude inquiry (Table 2 ) revealed an increase in the mean score of the participants' attitude after training, from $45.97 \pm 9.04$ to $45.97 \pm 9.04(p=0.004)$. The evaluation of the performance (Table 3 ) indicated an increase in the mean score of the subjects' performance after training, from $109.82 \pm 10.23$ to $113.46 \pm 9.46(p=0.001)$.

\begin{tabular}{|c|c|c|c|}
\hline Variables & Cluster & Absolute Frequency & $\%$ \\
\hline Academic degree & $\begin{array}{c}\text { Master } \\
\text { PhD student } \\
\text { PhD }\end{array}$ & $\begin{array}{c}42 \\
6 \\
19\end{array}$ & $\begin{array}{c}62.7 \\
9.0 \\
28.4\end{array}$ \\
\hline Marital status & $\begin{array}{l}\text { Unmarried } \\
\text { Married }\end{array}$ & $\begin{array}{l}24 \\
43\end{array}$ & $\begin{array}{l}35.8 \\
64.2\end{array}$ \\
\hline University type & $\begin{array}{l}\text { Public } \\
\text { Private }\end{array}$ & $\begin{array}{l}45 \\
22 \\
\end{array}$ & $\begin{array}{l}67.2 \\
32.8 \\
\end{array}$ \\
\hline Faculty member & $\begin{array}{l}\text { Yes } \\
\text { No }\end{array}$ & $\begin{array}{l}41 \\
26\end{array}$ & $\begin{array}{l}61.2 \\
38.8\end{array}$ \\
\hline academic rank & $\begin{array}{c}\text { Trainer } \\
\text { Assistant prof. } \\
\text { Associate prof. }\end{array}$ & $\begin{array}{c}51 \\
16 \\
2\end{array}$ & $\begin{array}{c}76.1 \\
20.9 \\
3.0\end{array}$ \\
\hline $\begin{array}{l}\text { Track record in theoretically } \\
\text { teaching the pediatrics class }\end{array}$ & $\begin{array}{l}\text { Yes } \\
\text { No }\end{array}$ & $\begin{array}{c}9 \\
58\end{array}$ & $\begin{array}{l}13.4 \\
86.6\end{array}$ \\
\hline $\begin{array}{l}\text { Track record in clinically } \\
\text { teaching the pediatrics class }\end{array}$ & $\begin{array}{l}\text { Yes } \\
\text { No }\end{array}$ & $\begin{array}{l}23 \\
44\end{array}$ & $\begin{array}{l}34.3 \\
65.7\end{array}$ \\
\hline $\begin{array}{l}\text { Track record in taking part in } \\
\text { physiological workshop }\end{array}$ & $\begin{array}{l}\text { Yes } \\
\text { No }\end{array}$ & $\begin{array}{l}40 \\
27 \\
\end{array}$ & $\begin{array}{r}59.7 \\
40.83 \\
\end{array}$ \\
\hline $\begin{array}{l}\text { Track record in participating in } \\
\text { the newborn-resuscitating } \\
\text { workshop }\end{array}$ & $\begin{array}{l}\text { Yes } \\
\text { No }\end{array}$ & $\begin{array}{l}24 \\
43\end{array}$ & $\begin{array}{l}35.8 \\
64.2\end{array}$ \\
\hline $\begin{array}{l}\text { Track record in participating in } \\
\text { breast feeding workshop }\end{array}$ & $\begin{array}{l}\text { Yes } \\
\text { No }\end{array}$ & $\begin{array}{l}28 \\
39\end{array}$ & $\begin{array}{l}41.8 \\
58.2\end{array}$ \\
\hline \multicolumn{2}{|c|}{ Standard deviation \pm Average age } & \multicolumn{2}{|l|}{$7.64 \pm 39.51$} \\
\hline
\end{tabular}

\begin{tabular}{|c|c|c|c|c|c|c|}
\hline \multirow{2}{*}{$\begin{array}{c}\text { Frequency } \\
\text { Score }\end{array}$} & \multicolumn{2}{|c|}{ Before } & \multicolumn{2}{|r|}{ After } & Test & $\mathbf{p}$ \\
\hline & No. & $\%$ & No. & $\%$ & \multirow{7}{*}{ Wilcoxon } & \multirow{7}{*}{$<0.001$} \\
\hline $0-5$ & 9 & 13.4 & 0 & 0 & & \\
\hline $6-10$ & 46 & 68.7 & \begin{tabular}{|l|}
27 \\
\end{tabular} & 40.3 & & \\
\hline 11-15 & 12 & 17.9 & 40 & 59.74 & & \\
\hline Total & 67 & 100 & 67 & 100 & & \\
\hline Median & \multicolumn{2}{|c|}{8} & \multicolumn{2}{|r|}{$\frac{11}{(10.14)}$} & & \\
\hline IQR & & & & $(10,14)$ & & \\
\hline \multicolumn{7}{|c|}{$\begin{array}{c}\text { Table 2. Comparison of Absolute and Relative Frequency Distribution } \\
\text { of the Subjects' Knowledge of the Educational Content Related to the } \\
\text { Newborn Care Based on Intended Midwifery Textbooks before and } \\
\text { after Intervention }\end{array}$} \\
\hline
\end{tabular}




\begin{tabular}{|c|c|c|c|c|c|c|}
\hline \multirow{2}{*}{ Frequency Score } & \multicolumn{2}{|c|}{ Before } & \multicolumn{2}{|c|}{ After } & Test & p \\
\cline { 2 - 5 } & No. & $\mathbf{\%}$ & No. & \% & & \\
\hline $14-44$ & 22 & 32.8 & 12 & 17.9 & Paired $t$ & \multirow{2}{*}{0.004} \\
\hline $43-70$ & 45 & 67.2 & 55 & 82.1 & $\mathrm{~T}=-3$ & \\
\hline Total & 67 & 100 & 67 & 100 & $\mathrm{df}=66$ & \\
\hline S.D. \pm mean & $9.04 \pm 45.97$ & $7.37 \pm 49 / 35$ & & \\
\hline Table 3. Comparison of the Absolute and Relative Frequency \\
Distribution Scores of Midwifery Teachers' Attitudes of Educational \\
Content of Neonatal Care Based on Midwifery Teaching before and \\
after Intervention \\
\hline
\end{tabular}

\begin{tabular}{|c|c|c|c|c|c|c|}
\hline \multirow{2}{*}{ Frequency Score } & \multicolumn{2}{|c|}{ Before } & \multicolumn{2}{|c|}{ After } & Test & p \\
\hline & No. & $\%$ & No. & $\%$ & \multirow{6}{*}{ Wilcoxon } & \multirow{6}{*}{0.001} \\
\hline $59-92$ & 7 & 10.3 & 4 & 6 & & \\
\hline $93-125$ & 60 & $\begin{array}{l}89.7 \\
\end{array}$ & 63 & 64 & & \\
\hline Total & 67 & 100 & 67 & 100 & & \\
\hline Median & \multicolumn{2}{|c|}{112} & \multicolumn{2}{|c|}{115} & & \\
\hline IQR & \multicolumn{2}{|c|}{$(103,117)$} & \multicolumn{2}{|c|}{$(109,121)$} & & \\
\hline \multicolumn{7}{|c|}{$\begin{array}{l}\text { Table 4. Comparison of Performance of the Midwifery Teachers in } \\
\text { Terms of the Educational Contents of Neonatal Care According to the } \\
\text { Intended Midwifery Textbooks before and after Intervention }\end{array}$} \\
\hline
\end{tabular}

\section{DISCUSSION}

This survey revealed that virtual education based on intended midwifery textbooks has increased the participants' knowledge, attitude and performance in regard to neonatal care. Varei et al. (2016) showed that the multimedia training program could increase the knowledge of nurses about safe injections $(\mathrm{p}<0.05) .{ }^{(12)}$ The results of a study conducted by Zanghi Abadzadeh et al. (2016) indicated that training in increasing the knowledge and attitude of midwifery students had played a significant role toward normal vaginal delivery $(\mathrm{p}<0.001) .(13)$

In Payman et al. (2015), educational intervention had been able to increase the mean scores of knowledge of high school girl students toward AIDS ( $\mathrm{p}<0.001)$.(14) The study carried out by Doblecki-Lewis et al. (2013) illustrated the positive impact of training on the increase in mean scores of Florida doctors' knowledge about Congo fever $(\mathrm{p}<0.001)$.

The survey conducted by Bolbl Hagighi et al. (2007) showed an increase in mean scores of knowledge after training $(p=0.0001)$ and $(p=0.003) .{ }^{(15)}$ In similar way, Akhundzadeh et al. (2005) had been able to increase the mean scores of knowledge of midwives in the labor ward of hospitals in Guilan University of Medical Sciences ( $\mathrm{p}<0.005)$. (16)

Rahimi Kian et al. (2006) likewise illustrated that after education, the knowledge and practice score of midwifery graduates was significantly increased in offering delivery services. Therefore, training has a positive effect on increasing knowledge and subsequently improve the performance of midwives $(p=0.0001) .(17)$ Parsinia et al. (2007) also showed the positive impact of education on increasing the knowledge of male and female students of Islamic Azad University of Karaj in terms of family planning $(\mathrm{p}<0.05)$.(18)

Moreover, in a research conducted by Coppens et al. (2017), the OSPI-Europe learning program improved the attitude of general practitioners towards suicide prevention, depression and its treatment, as well as general practitioners' confidence in dealing with depression and suicide $(\mathrm{p}<0.001) .(19)$

The results of the above studies were similar to our study, which reveal the positive effect of education on increasing knowledge, improving attitude and performance. In addition, training has increased knowledge, attitude and performance in many studies. $(20,21$, and 22) In the present study, the training of the neonatal care content based on intended midwifery textbooks has been able to increase the knowledge, attitude and performance of midwifery teachers. In few studies, education had not been able to increase the performance score. For example, in the study of Mohammadi et al. (2003), the participation of trainers in the educational workshop had a positive effect on increasing their knowledge and attitudes toward effective clinical education, but their performance score did not significantly increase,(21) which could be arisen out of obstacles to the implementation of the curriculum e.g. complexity and changing situation of the clinical environment, the high number of students, the lack of collaboration of medical personnel, planning principles of clinical activities, inspection of educational activities of trainers, and so forth.

Since teachers are extremely occupied with work and it is difficult to convene them nationwide to participate in the study, the researchers decided to develop a virtual neonatal care course according to both intended midwifery textbooks and questionnaires. The number of questions was as low as possible in developing questionnaire, so midwifery teachers would be more willing to complete it. One of the drawbacks of the study was that it was not clear whether the participants had attended virtual classroom and received the contents or not. In order to cope with this problem, the researchers were pursuing the activity of the instructors through phone calls and texting

The results of the present study showed an increase in knowledge of midwifery teachers, from moderate to the desired level after training. Pre- training attitude scores, although increased after education, was as good as posttraining, indicating that educators themselves recognize the importance of the intended midwifery resources, so midwifery policymakers should pay more attention to developing midwifery resources in terms of educating midwifery student. The pre- and post-performance of the subjects, although desirable, had been improved due to taking part in this educational course.

\section{CONCLUSIONS}

Overall, the knowledge, attitude and performance of midwifery instructors participating in the study improved after using intended midwifery textbooks. It is, therefore, crucial to theoretically review the educational content of the midwifery discipline based on ICM and also intended midwifery textbooks should be paid special attention by authorities who design the midwifery curriculum.

\section{ACKNOWLEDGEMENT}

This article is adapted from a research project empowered by the Research Deputy of Tehran University of Medical Sciences.

\section{REFERENCES}

[1] Brucker MC. Conference Proceedings: Midwifery in American Institutes of Higher Education: Women's Work, Vocations and the 21st Century. 2009. https://files.eric.ed.gov/fulltext/EJ870101.pdf 
[2] International Definition of the Midwife. 2017. https://www.internationalmidwives.org

[3] Essential Competencies for Midwifery Practice. 2018. https://www.internationalmidwives.org/ourwork/policy-and-practice/essential-competencies-formidwifery-practice.html

[4] Marshall J, Raynor M. Introduction. In: Myles textbook for Midwives. 16 th edn. Elsevier 2014: p. 3-25.

[5] Korekolom Mamaee. 2018. http://nurse.nkums.ac.ir/get_file.aspx?fn=Uploaded/Use rs/2/36/korekolom\%20mamaee.pdf

[6] Sanjeshp.ir 2018 http://www.sanjeshp.ir/FileHandler.ashx?Id=40813\&ty pe=application $/ p d f$

[7] Zaighami R, Faseleh M, Jahanmiri SH, et al. Nursing students' viewpoints about the problems of clinical teaching. JQUMS 2004;8(1):51-5.

[8] Marshall J, Raynor M. Introduction. In: Myles textbook for Midwives. 16 $6^{\text {st }}$ edn. Elsevier 2016: p. 3-25.

[9] Ahmady S, Yazdi L. Exploring the midwifery training challenges in Iran from the viewpoint of faculty members and graduates of this field: content analysis. Journal of Medical Education 2016;15(2):82-9.

[10] Enkin M, Keirse M, Neilson J, et al. A Guide to effective care in pregnancy \& childbirth. $3^{\text {rd }}$ edn. London: Oxford University Press, Published Online 2013.

[11] Adib-Hajbaghery M, Mohammad-Ehsan A, Arani SJ. The effect of web-based education on learning in medical sciences students: a review study. Iranian Journal of Medical Education 2017;17:298-310.

[12] Varaei SH, Mamashli L, Ghiyasvandian SH. The effect of multimedia education program on knowledge and practice of nurses about safe injection. Iran Journal of Nursing 2016;29(103):68-77.

[13] Zangiabadizade M, Saeediyan M, Shahinfar S. Comparing the effects of role-playing and multimedia-based teaching methods on midwifery students' knowledge and attitude towards vaginal delivery. Iranian Journal of Medical Education 2017;17:60-8.

[14] Peyman N, Jangi M. The effect of educational intervention on knowledge, attitude and performance of high school girl students about AIDS. International Journal of Pediatrics 2015;3(4):833-9.
[15] Haghighi BN, Hossein EM, Delvarianzadeh M, et al. Effects of education on midwifery students' knowledge and skill in neonatal resuscitation. J Med Education Development Center 2007;4(2):116-24.

[16] Akhundzadeh E, Geranmaye M. The effect of education on pain relief pain method on knowledge, attitude and practice of midwives of the gynecology department of hospitals of Guilan University of Medical Sciences. GUMS 2006.

[17] Rahimikian F, Mirmolaei T, Samizadeh Z, et al. Evaluation of knowledge and practice of newly graduated midwives in normal vaginal delivery in hospitals affiliated to Tehran University of Medical Sciences. Iran J Med Edu 2007;7(1):51-7. http://ijme.mui.ac.ir/article-1-626fa.html

[18] Parsinia M, Ashkvari P, Babaei G. Comparative study on the effect of family planning education on knowledge and attitude of students Girl and son of Islamic Azad University of Karaj, about family planning. Med Sci J Islamic Azad Univ Tehran Med Branch 2010:69-72.

[19] Coppens E, Van Audenhove C, Gusmao R, et al. Effectiveness of General Practitioner training to improve suicide awareness and knowledge and skills towards depression. Journal of Affective Disorders 2018;227:1723.

[20] Jha N, Bajracharya O, Shankar PR. Knowledge, attitude and practice towards medicines among school teachers in Lalitpur district, Nepal before and after an educational intervention. BMC Public Health 2013;13:652.

[21] Mohammadi B, Valizadeh S, Dizeji SL. The impact of teaching on knowledge, attitude and practice of nursing and midwifery instructors in regard to clinical education effective behaviors, Tabriz University of Medical Sciences, 2002. Iran J Med Edu 2003;3(1):61-9. http://ijme.mui.ac.ir/article-1-179-en.html

[22] Salimi T, Khodayarian M, Rajabioun H, et al. A survey on viewpoints of nursing and midwifery students and their clinical instructors at Faculty of Nursing and Midwifery of Shahid Sadoughi University of Medical Sciences towards clinical education during 2009-2011. JMED 2012;7(3):6778. 